\section{INTERRUPÇÃO PRECOCE DO ALEITAMENTO MATERNO EXCLUSIVO: EXPERIÊNCIA COM MÃES DE CRIANÇAS EM CONSULTAS DE PUERICULTURA}

\author{
Early interruption of exclusive breastfeeding: experience with \\ mothers of children in child-care consultations
}

Interrupción precoz del amamantamiento materno exclusivo:
experiencia de madres de niños de las consultas de puericultura
Artigo Original

\section{RESUMO}

Objetivo: Identificar os fatores que levam as mães a interromper o aleitamento materno exclusivo antes do sexto mês. Métodos: Estudo qualitativo realizado com 12 mães que participavam de rodas de conversas como estratégia dialógica de educação em saúde para proporcionar uma troca de experiências sobre o a importância do aleitamento materno exclusivo. Realizou-se o estudo em uma Unidade Básica de Saúde de Tauá/CE, durante o mês de março 2015. Os dados foram coletados por meio de entrevista semiestruturada, analisados de forma temática, dos quais emergiram duas categorias: "Desmame precoce porque o leite é fraco" e "Desmame precoce por interferência familiar e questões culturais". Resultados: As entrevistadas reconhecem a importância do aleitamento materno, no entanto, são influenciadas por familiares e por questões culturais, que somadas à falta de orientação, fazem-nas achar que o seu "leite é fraco", levando ao desmame precoce. Conclusão: A influência familiar, as questões culturais e a falta de apoio têm impactado negativamente o aleitamento exclusivo antes do sexto mês de vida. Assim, cabe aos profissionais de saúde investir nas questões da promoção, proteção e apoio ao aleitamento, devendo ser discutidas de forma integral, individual, familiar e com todos os segmentos da sociedade.

Descritores: Aleitamento Materno; Desmame Precoce; Educação em Saúde.

\section{ABSTRACT}

Objective: To identify the factors that lead mothers to discontinue exclusive breastfeeding prior to the sixth month. Methods: Qualitative study conducted with 12 mothers attending circles of conversation as a dialogic strategy of health education to provide an exchange of experiences about the importance of exclusive breastfeeding. This study was held in a Primary Health Unit in Tauá, Ceará, Brazil, during March 2015. Data was collected through semi-structured interviews and submitted to thematic analysis, from which two categories emerged: "Early weaning due to weak milk"; "Early weaning due to family interference and cultural issues". Results: The interviewees recognize the importance of breastfeeding; nevertheless, they are influenced by relatives and cultural issues which, in addition to the lack of orientation, make them believe that their "milk is weak", leading to early weaning. Conclusion: Family influence, cultural issues and lack of support have posed a negative impact to exclusive breastfeeding prior to the sixth month of life. It is, therefore, the health professionals' responsibility to invest in subjects related to breastfeeding promotion, protection and support, which must be discussed in a comprehensive way, with individuals, family and all segments of the society.

Descriptors: Breastfeeding; Weaning; Health Education.
Recebido em: 28/06/2015 Revisado em: 08/07/2015 Aceito em: 05/08/2015 


\section{RESUMEN}

Objetivo: Identificar los factores que llevan a las madres parar el amamantamiento materno exclusivo antes del sexto mes. Métodos: Estudio cualitativo realizado con 12 madres que participaban de las charlas como estrategia dialógica de educación en salud para promover el cambio de experiencias sobre la importancia del amamantamiento materno exclusivo. El estudio se realizó en una Unidad Básica de Salud de Tauá/CE durante el mes de marzo de 2015. Los datos fueron recogidos a través de una entrevista semiestructurada, analizadas de manera temática de la cual surgieron dos categorías: "Destete precoz porque la leche es débil" y "Destete precoz debido la interferencia familiar y cuestiones culturales". Resultados: Las entrevistadas reconocen la importancia del amamantamiento materno, sin embargo, son influenciadas por los familiares y cuestiones culturales que asociadas a la falta de orientación las hace pensar que su "leche es débil" lo que conlleva al destete precoz. Conclusión: La influencia familiar, las cuestiones culturales y la falta de apoyo han comprometido negativamente el amamantamiento exclusivo antes del sexto mes de vida. De esa manera, compete a los profesionales de la salud investir en las cuestiones de la promoción, la protección y el apoyo para el amamantamiento que deben ser discutidas de una manera integral, individual, familiar y con todos los segmentos de la sociedad.

Descriptores: Lactancia Materna; Destete; Educación en Salud.

\section{INTRODUÇÃO}

Tratando-se de atenção básica à saúde, a Estratégia Saúde da Família, criada em 1993, vem se solidificando como um dos eixos estruturantes do Sistema Único de Saúde (SUS), através de um movimento de expressiva expansão de cobertura populacional, melhorando muito o acesso da população às ações de saúde. Levando em conta esse processo, o Pacto pela Redução da Mortalidade Materna e Neonatal, o Pacto pela Vida e a Política Nacional de Atenção Básica surgiram para colaborar como instrumentos para o fortalecimento da saúde da criança no âmbito do $\operatorname{SUS}^{(1)}$.

A prática do aleitamento materno se configura como uma das medidas essenciais para a saúde e desenvolvimento da criança no início da vida. Além de agregar um benefício calórico e proteico, o leite materno confere a proteção imunitária necessária para a criança no primeiro ano de vida. Segundo a literatura, recém-nascidos alimentados exclusivamente ao seio têm um risco menor de morte por diarreia e doenças respiratórias, além de serem beneficiados cognitiva e motoramente, e terem os indicadores gerais da saúde aumentados ${ }^{(2)}$.

Nos últimos tempos, o aleitamento materno exclusivo (AME) vem sendo cada vez mais incentivado, tendo como base as evidências científicas. É recomendação da Organização Mundial de Saúde (OMS) que a amamentação seja exclusiva até o sexto mês de vida, no entanto, o aleitamento materno (AM) deve ser mantido até os dois anos ou mais ${ }^{(3)}$.

O AME é caracterizado pela OMS como a oferta apenas de leite, permitindo-se apenas gotas de medicamentos ou vitaminas, sem chás nem água. Quando uma criança recebe, antes de completar 180 dias de vida, outros alimentos que não o leite materno, pode-se dizer que foi iniciado o processo de desmame de forma precoce ${ }^{(4)}$.

O exercício de sucção feito pela criança para retirar o leite da mama é de extrema importância para o adequado desenvolvimento da sua cavidade oral, conformando melhor o palato duro, alinhando os dentes de forma correta e proporcionando uma boa oclusão dentária. O uso de chupetas e mamadeiras faz com que o assoalho da cavidade nasal se eleve, diminuindo o espaço para a passagem de ar. Dessa forma, o desmame precoce pode prejudicar a deglutição, a respiração, a mastigação e a articulação dos sons da fala, ocasionando má oclusão dentária, respiração bucal e alteração motora-oral ${ }^{(1)}$.

Desde 1981, o Brasil vem passando por transformações importantes no cenário do aleitamento materno, no entanto, o desmame precoce é ainda uma realidade que predomina. Supõe-se que uma das explicações para essa realidade seja o fato de que, apesar de os profissionais de saúde se mostrarem favoráveis à amamentação, às vezes eles não estão próximos a ponto de vivenciarem o insucesso da mulher no processo de lactação $0^{(5)}$.

De acordo com um levantamento feito pela OMS, em quase todos os países do mundo, somente $35 \%$ das crianças menores de quatro meses são amamentadas no peito exclusivamente, sendo essa prática, portanto, aquém do que é recomendado pela entidade ${ }^{(4)}$.

Em algumas situações, a amamentação é interrompida, mesmo a mãe manifestando desejo de mantê-la. Dentre as razões mais frequentes para interrupção precoce, estão: leite insuficiente, rejeição do seio pela criança, trabalho da mãe fora do lar, hospitalização da criança e problemas nas mamas. Várias dessas situações podem ser evitadas ou manejadas $^{(1)}$.

Durante as consultas de puericultura e visitas puerperais feitas ao longo do curso de residência de uma das autoras, foi observado que a maioria das mães amamenta exclusivamente por um período muito curto, introduzindo fórmulas artificiais inadequadas para crianças nos primeiros dias de vida, fato que preocupa os profissionais. A Residência Integrada em Saúde (RIS), oferecida pela Escola de Saúde Pública (ESP) do Ceará, compõe uma modalidade de ensino de pós-graduação lato sensu, em regime de tempo integral, 
com dedicação exclusiva, tendo como característica a educação para o trabalho, por meio da aprendizagem em serviço, no âmbito dos Sistemas Municipais de Saúde (SMS) ou região de saúde correspondente, com envolvimento de outras instituições, universitárias ou não( ${ }^{(6)}$.

Assim, o interesse pelo tema surgiu ao longo da residência, ao realizarem-se visitas puerperais e consultas de puericultura, nas quais se percebeu que, apesar do auxilio profissional e dos programas assistenciais voltados para essa temática, a interrupção do AME vem acontecendo cada vez mais cedo. Então, buscar compreender por que isso acontece é o que torna justificável este estudo. Já a relevância se ampara no fato de que esse é um debate socialmente importante para a saúde pública, por permitir a discussão e o fortalecimento da saúde da criança.

O profissional de saúde exerce um papel fundamental para minorar as baixas taxas de AME, mas, para isso, precisa estar preparado, pois, além de competência, precisa ter um olhar atento, abrangente, sempre levando em consideração os aspectos emocionais, a cultura familiar, a rede social de apoio à mulher; enfim, deve reconhecê-la como protagonista do seu processo de amamentar, valorizando-a, escutando-a e empoderando-a, utilizando como ferramentas as práticas de educação em saúde, que correspondem à transmissão de informação, com o intuito de mudar um comportamento pessoal em relação à própria saúde, assim como capacitá-la para agir com consciência diante da realidade cotidiana ${ }^{(1)}$.

Diante dessa problemática, objetivou-se identificar os fatores que levam as mães a interromper o aleitamento materno exclusivo antes do sexto mês.

\section{MÉTODOS}

Trata-se de um estudo descritivo com abordagem qualitativa. A pesquisa qualitativa procura entender um problema sob a perspectiva dos sujeitos que o vivenciam em seu cotidiano, sua satisfação, sentimentos, desejos, desapontamentos, surpresas e outras emoções ${ }^{(7)}$. Escolheuse esse tipo de estudo porque esse método busca conhecer a variável estudada tal como se apresenta, seu significado e o contexto no qual ela se insere, aplicando-se ao estudo das percepções, das histórias, das relações, das crenças, das representações e das opiniões, produtos das interpretações que os humanos fazem a respeito de como vivem, constroem seus artefatos e a si mesmos, como sentem e pensam ${ }^{(8)}$.

O estudo foi desenvolvido em uma Unidade Básica de Saúde localizada em Tauá/CE, a qual é constituída por três Equipes de Saúde da Família. A unidade oferta serviços de promoção da saúde e prevenção de doenças, contando com equipe de referência (médico, enfermeiro e dentista), com o Núcleo de Apoio à Saúde da Família (NASF) e com profissionais do curso de residência - enfermeiros, nutricionistas, psicólogos e fisioterapeutas. A escolha por essa unidade ocorreu no intuito de realizar uma intervenção no território de atuação da residência.

O período da coleta de dados ocorreu em março de 2015. A participação foi voluntária, mediante assinatura do Termo de Consentimento Livre e Esclarecido. A coleta foi feita por meio de questões norteadoras sobre a importância da amamentação exclusiva, sua duração e os motivos que levaram à sua interrupção. Essas questões foram abordadas e discutidas com as mães que participaram das rodas de conversa voltadas para a promoção do aleitamento materno exclusivo, as quais foram gravadas com auxílio de um gravador portátil.

A roda de conversa se configura como um método de ressonância coletiva que se traduz como a criação de espaços de diálogo nos quais as pessoas podem se expressar, assim como escutar os outros e a si mesmas. Tal estratégia corrobora para a construção da autonomia dos sujeitos através da problematização, da troca de experiências e da reflexão para a ação ${ }^{(9)}$. A informalidade da roda de conversa é um exemplo de espaço democrático de aprendizagem, onde há inclusão e cooperação dos sujeitos na construção do processo educativo. Ao longo da roda, o profissional (facilitador) deverá se esforçar para desencadear tanto a reflexão quanto a discussão do tema, por meio da troca e compartilhamento de problemas e soluções ${ }^{(10)}$.

Fizeram parte do estudo as mães que estavam com crianças em acompanhamento de puericultura na unidade de saúde e que participaram das rodas de conversa. A forma de recrutamento dos participantes deu-se mediante anúncio público, através do qual as interessadas procuraram os pesquisadores responsáveis no local e data agendados na instituição. As mães que não participaram das rodas não fizeram parte do estudo. Assim, a amostra totalizou 12 participantes.

Analisaram-se as entrevistas de forma temática, evidenciando as ideias centrais ou nucleares dos discursos, as quais emergem das respostas obtidas questão por questão. Esse tipo de análise é formado por três etapas: a pré-análise, que consiste na leitura flutuante do material obtido, por meio das transcrições das entrevistas; a exploração do material, que se refere à codificação das informações contidas no material, ou seja, recortes do texto, classificando-os de acordo com as categorias temáticas; e, por fim, o tratamento dos resultados e sua interpretação, que correspondem à classificação das ideias centrais em temas principais, os quais resultam do agrupamento de elementos encontrados, propondo interpretações a respeito dos objetivos propostos ${ }^{(8)}$.

Dessa forma, após a leitura e releitura do material, chegou-se à construção das seguintes categorias temáticas: "Desmame precoce porque o leite é fraco" e "Desmame precoce por interferência familiar e por questões culturais". 
$\mathrm{Na}$ apresentação dos resultados, as participantes foram identificadas com a palavra "mãe", seguida de um número.

O projeto foi submetido ao Comitê de Ética da Escola de Saúde Pública do Ceará, com parecer de aprovação ${ }^{\circ}$ 973.454, e seguiu a Resolução 466/12(11) do Conselho Nacional de Saúde, que regulamenta as normas de pesquisa com seres humanos.

\section{RESULTADOS E DISCUSSÃO}

Na sequência, são apresentadas as categorias temáticas que classificam os motivos que levaram as mães ao desmame precoce.

De acordo com os dados obtidos nas entrevistas, a maioria das participantes do estudo amamentou exclusivamente no máximo até o quarto mês de vida de suas crianças, o que confirma os baixos indicadores de aleitamento materno exclusivo (AME). Apesar de tantas vantagens proporcionadas pelo aleitamento, o resultado está muito distante do que é preconizado pela Organização Mundial de Saúde. A amamentação sofre influências socioculturais, dessa forma, não existem causas isoladas para o desmame precoce, e sim uma relação de fatores existentes entre a mãe, o filho e o contexto social em que se inserem ${ }^{(12)}$.

\section{"Desmame precoce por o leite ser fraco"}

Esta categoria evidencia que as entrevistadas, ao serem indagadas sobre os motivos que levaram ao desmame precoce, revelaram "leite fraco" e um "um leite que não sustenta o bebê" como os principais motivos para a complementação precoce da alimentação do bebê, como visto nas falas a seguir:

"[...] Eu sei que é importante amamentar até o sexto mês de vida do bebê. Mas não ganhava peso de jeito nenhum, estava já em risco pra desnutrição. Ai a pediatra mandou eu introduzir outros tipos de alimento e continuar dando a mama [...]." (Mãe 11)

"[...] Quando eu cheguei da maternidade, eu comecei a dar leite de gado, porque meu leite era fraco e quase não tinha, então eu tinha que dar alguma coisa. Até veio a enfermeira e a nutricionista conversar comigo aqui em casa, mas eu não tenho condição de comprar o NAN não, é muito caro [...]." (Mãe 10)

Do ponto de vista biológico, são raras as intercorrências que impossibilitam a amamentação. No entanto, esse conceito de "leite fraco" foi introduzido na cultura brasileira pelos higienistas do século XIX, tendo em vista a dificuldade de se explicar os motivos do insucesso das mães com a amamentação. O conceito foi bem assimilado e tornou-se uma das construções sociais usadas como explicação para o desmame precoce ${ }^{(13)}$.

A maioria das mães que interrompeu o AME o fez porque considerava o leite fraco ou insuficiente para suprir as necessidades nutricionais da criança. A aparência aguada do leite materno, principalmente do colostro, serve de fundamentação para essa crença e faz com que muitas mães acreditem que ele não serve para atender às demandas da criança ${ }^{(14)}$.

O mito de que o leite não atende às necessidades do bebê por ser fraco apoia-se no fato de o bebê mamar e aparentar não ficar satisfeito. Nessa situação, é importante ressaltar que o leite humano contém todos os nutrientes de que a criança necessita, é de fácil digestão, e seu aspecto aguado é uma característica normal; portanto, o leite materno é sempre o mais indicado e, salvo algumas exceções, está sempre em boas condições para o consumo da criança ${ }^{(14)}$.

O estudo em questão corrobora com pesquisa realizada em Teresina/PI, em 2008, com onze mães que desmamaram precocemente. As entrevistadas apontaram como relevantes para a efetivação do desmame precoce os problemas relacionados à "falta de leite", "leite fraco", problemas mamários e a recusa do bebê em pegar o peito ${ }^{(15)}$.

Ressalta-se que, atualmente, estamos perdendo o suporte cultural que havia em épocas passadas, nas quais as avós transmitiam às mães informações e treinamento para o aleitamento materno. Portanto, é relevante que a mulher sinta-se amparada nas suas dificuldades, para que possa assumir com tranquilidade o papel de mãe que amamenta seu filho. Cabe aos profissionais de saúde o compromisso de realizar um atendimento de qualidade a essas mães, de modo a tornar a amamentação um ato de prazer, e não uma obrigação, reforçando, ao mesmo tempo, a fisiologia da lactação humana, que atualmente não tem sido valorizada ${ }^{(15)}$.

\section{"Desmame precoce por interferência familiar e questões culturais"}

Nesta categoria, as participantes destacaram influências familiares e questões culturais em relação ao desmame precoce. Na prática do aleitamento materno, podem surgir recomendações características de cada família, vistas como de grande importância para a análise deste estudo. Também foram identificadas vivências reguladas em crenças e tradições familiares, caracterizando a amamentação como um ato sociocultural. Isso pode ser constatado por meio das falas a seguir:

"[...] Porque a minha mãe disse que não era para eu só amamentar não, que já podia dar outras coisas também, senão ela não ia parar nunca. A minha irmã só deu o peito, ai o menino dela só veio deixar de mamar agora [...]." (Mãe 8) 
“[...] No começo eu dava só o peito, mas ai ela dava trabalho para dormir. Ai minha mãe começou a dar leite ninho para ela de noite. Ai ela dormia a noite todinha [...]." (Mãe 9)

À luz da atual investigação, pode-se perceber que as práticas alimentares têm sido erroneamente recomendadas pelos familiares, como bem mostram as falas. Uma justificativa apontada para essa questão refere-se ao fato de a nutriz, em meio às transformações que representa a maternidade, tornar-se mais sensível às influências externas a respeito dos cuidados com seu filho, sendo os familiares os responsáveis pela maior parcela de interferências sobre a decisão de amamentar ou não ${ }^{(16)}$.

A lactação é vista pelas mães como um ato determinado pela vivência da lactante em família, uma experiência repassada de geração para geração. Nesse sentido, os familiares exercem forte influência quando se tratam de alimentação, nutrição e hidratação da criança. Diante disso, as experiências familiares, culturais e condições de vida podem influenciar essa prática ${ }^{(17)}$.

Nesse contexto, o familiar, no desejo de ajudar, acaba provocando um desequilíbrio na dinâmica do aleitamento exclusivo, incentivando o uso de mamadeiras, chás e até leite artificial, contribuindo, consciente e/ou inconscientemente, para o desmame precoce. As distorções de informação oriunda de familiares, as crenças e a comodidade, portanto, acabam por estimular a introdução de alimentos sólidos e líquidos antes de a criança chegar ao sexto mês de vida ${ }^{(18)}$.

Essa associação entre o contato familiar e uma menor duração do AME, identificada no estudo, demonstra que o aleitamento é um processo altamente influenciado culturalmente, o que torna necessária a implantação de estratégias de promoção de saúde dentro de um contexto adequado à população-alvo.

O convívio social é imprescindível para a construção do aprendizado, mas, por ser a família o primeiro e principal núcleo de convívio do ser humano, é por meio dela que se constrói e se perpetua, com o passar do tempo, grande base dos nossos conhecimentos. Nos ensinamentos compartilhados entre os familiares, normalmente são transferidas as experiências de vida, assentando-se de acordo com as crenças e valores próprios da cultura introduzida no ambiente familiar ${ }^{(19)}$

Dessa forma, objetivando legitimar a sua visão de mundo sobre a amamentação, é mister discutir com a mulher primeiramente, porque é uma decisão dela amamentar. $\mathrm{O}$ retorno às atividades remuneradas fora do lar é outra preocupação constante da mulher que decide amamentar seu filho, porque precisa de ajuda para conciliar os seus diversos afazeres, em especial no caso das primíparas, cujo apoio familiar é indispensável.
Enfim, devem-se debater valores e crenças de maneira que possam justificar a ordem estabelecida, pois é através da promoção, proteção e apoio à amamentação que se depara com uma das formas de reprodução das relações sociais e de sua concepção de mundo em relação aos valores sociais da amamentação( ${ }^{(20)}$.

\section{CONSIDERAÇÕES FINAIS}

Os resultados e discussão dos dados deste estudo possibilitaram considerar o contexto em que se insere a problemática do desmame precoce, bem como alcançar o objetivo deste estudo. Com base nos relatos, constatou-se que, embora as mães entrevistadas distingam a importância do aleitamento materno, foram influenciadas pela família e por questões culturais, as quais, somadas à falta de orientação, fazem-nas achar que o seu leite é fraco, levando ao desmame precoce, antes do sexto mês de vida do bebê.

É possível referir outras razões que o expliquem, ligadas ao ambiente, ao emocional, à escolha pessoal, dentre outras questões que não foram aprofundadas neste estudo.

Assim, cabe aos profissionais de saúde investir na promoção, proteção e apoio ao aleitamento, não podendo ser discutidos de forma isolada, e sim de forma integral, individual, familiar e com todos os segmentos da sociedade.

\section{REFERÊNCIAS}

1. Ministério da Saúde (BR), Departamento de Atenção Básica, Secretaria de Atenção à Saúde. Saúde da criança: nutrição infantil. Brasília: Ministério da Saúde; 2009. (Cadernos de Atenção Básica, n.23.)

2. Bezerra VLVA, Nisiyama AL, Jorge AL, Cardoso RM, Silva EF, Tristão RM. Aleitamento materno exclusivo e fatores associados a sua interrupção precoce: estudo comparativo entre 1999 e 2008. Rev Paul Pediatr. 2012;30(2):173-9.

3. Giuliani NR, Oliveira J, Santos BZ, Bosco VL. O início do desmame precoce: motivos das mães assistidas por serviços de puericultura de Florianópolis/SC para esta prática. Pesq Bras Odontoped Clin Integr. 2012;12(1):53-8.

4. Salustiano RPQ, Diniz ALD, Abdallah VOS, Pinto RMC. Fatores associados a duração do aleitamento materno em crianças menores de seis meses. Rev Bras Ginecol Obstet. 2012;34(1):28-3.

5. Batista KRA, Farias MCAD, Melo WSN. Influência da assistência de enfermagem na prática da amamentação no puerpério imediato. Saúde Debate. 2013;37(96): $130-8$. 
6. Escola de Saúde Pública do Ceará, Secretaria de Saúde do Estado do Ceará, Governo do Estado do Ceará. Regimento aprovado por Reunião Ordinária da COREMU-RIS-ESP/CE, Fortaleza: ESPCE; 2013.

7. Kassada DS, Marcon SS, Waidman MAP. Percepções e práticas de gestantes atendidas na atenção primária frente ao uso de drogas. Esc Anna Nery Rev Enferm. 2014;18(3):428-34.

8. Minayo MCS. O desafio do conhecimento: pesquisa qualitativa em saúde. $11^{\mathrm{a}}$ ed. Rio de Janeiro: Abrasco; 2008.

9. Ramos LS, Beck CLC, Silva GM, Silva RM, Dissen CM. Estratégia de roda de conversa no processo de educação permanente em saúde mental. Rev Rene. 2013;14(4):845-53.

10. Mandra PP, Silveira FDF. Satisfação de usuários com um programa de roda de conversa em sala de espera. Audiol Commun Res. 2013;18(3):186-93

11. Ministério da Saúde (BR), Conselho Nacional de Saúde. Resolução n ${ }^{\circ}$ 466, de 12 de dezembro de 2012. Diário Oficial da União, Brasília, 13 jun 2013, seção 1, p. 59.

12. Santos JS, Andrade M, Silva JLL. Fatores que influenciam no desmame precoce: implicações para o enfermeiro de promoção da saúde na estratégia de saúde da família. Informe-se em Promoção Saúde. 2009;5(2):26-9.

13. Souza NKT, Medeiros MP, Silva MA, Cavalcanti SB, Dias RS, Valente FA. Aspectos envolvidos na interrupção do aleitamento materno exclusivo. Comun Ciênc Saúde. 2011;22(4):231-8.

14. Marques ES, Cotta RMM, Priore SE. Mitos e crenças sobre o aleitamento materno. Ciênc Saúde Coletiva. 2011;16(5):2461-8.
15. Araújo OD, Cunha AL, Lustosa LR, Nery IS, Mendonça RCM, Campelo SMA. Aleitamento materno: fatores que levam ao desmame precoce. Rev Bras Enferm. 2008;61(4):488-92 .

16. Silva WF, Guedes ZCF. Tempo de aleitamento materno exclusivo em recém-nascidos prematuros e a termo. Rev CEFAC. 2013;15(1):160-171.

17. Silva NM, Waterkemper R, Silva EF, Cordova FP, Bonilha ALL. Conhecimento de puérperas sobre amamentação exclusiva. Rev Bras Enferm. 2014;67(2):290-5.

18. Machado MOF, Haas VJ, Stefanello J, Nakano AMS, Sponholz FG. Aleitamento materno: conhecimento e prática. Rev Esc Enferm USP. 2012;46(4):809-15.

19. Martins MKS, Teodoro IPP, Sampaio AMA, Martins AKS, Cerqueira GS, Freitas APF et al. A influência da cultura familiar na prática do aleitamento materno. EFDeportes.com [periódico na Internet]. 2012 [acesso em 2015 Mar 12];17(169). Disponível em: http://www. efdeportes.com/efd169/a-cultura-familiar-na-praticado-aleitamento.htm

20. Alves VH, Rodrigues DP, GregórioVRP, Branco MBLR, Souza RMP, Alves CMCSH. Reflexões sobre o valor da amamentação como prática de saúde: uma contribuição da enfermagem. Texto \& Contexto Enferm. 2014;23(1):203-10.

\section{Endereço para correspondência:}

Maiara Gomes Rocha

Escola de Saúde Pública do Ceará - ESP/CE

Av. Antônio Justa, 3161

Bairro: Meireles

CEP: 60165-090 - Fortaleza - CE - Brasil

Email: maiara.grocha@gmail.com 